\title{
BANANEN EN BACOVEN
}

DOOR

FRED, OUDSCHANS DENTZ

Een der bekendste vruchten in de tropen is de pisang. Met recht noemde Alexander van Humboldt haar ,,de steun des levens in de tropen". De Musa- soort, sedert onheugelijke tijden in alle tropische deelen der wereld bekend als een der nuttigste voedingsgewassen, zij moge banaan, bacove, plantain of pisang worden genoemd, is voor millioenen menschen wat rijst is voor Chineezen en Hindoes, tarwe voor de Europeanen, aardappelen voor de Ieren en mais of mielies voor de bewoners van Afrika en Amerika.

Linnaeus veronderstelde, dat de Bihai Heliconinia humulis L., inheemsch in Venezuela, de moederplant van de banaan zou zijn, en hij noemde de plant Musa Paradisidiaca, meenende, dat de bladeren (en niet het vijgenblad) de eerste dekking onzer stamouders in het paradijs zouden zijn geweest, en deze vrucht de verboden vrucht, welke moeder Eva had misleid. In zijn werk De Natuur der Tropen zegt Alfred Russel Wallace: ,,Met recht mag de plantain de roem der tropen worden genoemd en Linnaeus deed wel om aan deze soort den naam van Musa Paradisidiaca te geven".

Waar de bakermat van deze plant is, is niet uitgemaakt. Volgens sommige schrijvers was de banaan in Amerika al bekend vóór de ontdekking van dat werelddeel door Columbus, en enkele andere reizigers beweren, dat de plant daar inheemsch was. Nog anderen zeggen, dat de plant in Zuid-Amerika inheemsch is, terwijl weer anderen meenen, dat de plant uit Afrika, van de kust van Guinea, naar de Canarische eilanden en van daar door de Spanjaarden naar West-Indië werd overgebracht.

De Musa's zijn door haar lichtgroene bladeren, haar sappigen stam en haar prachtige vrucht- en bloesemtrossen, die zich uit haar kroon ontwikkelen, de gewassen, die het meest de aandacht trekken van hen, die in de tropen komen. Het aantal variëteiten

$$
-246-
$$


is zeer groot. De twee hoofdsoorten, welke wij hier behandelen, zijn de banaan, in het Engelsch plantain, in het Spaansch plátano, in het Negerengelsch baäna, in het Papiamentoe banana, in het Arrowaksch prattana genoemd, een vrucht, die niet rauw gegeten wordt, maar gekookt, geroosterd of gebakken, en de bacove.

De bananen, die niet naar Europa uitgevoerd worden vormden in Suriname het hoofdvoedsel der slaven en zijn nog steeds het volksvoedsel bij uitnemendheid. Gekookt (als boomrijpe groene vruchten) worden zij met bakkeljouw (gezouten visch) genuttigd. Geroosterd zijn zij een smakelijk voedsel met kaas, ham of boter. Rijpe bananen worden, in de lengte doorgesneden, in schijven en in boter gebakken. $\mathrm{Zij}$ doen denken aan beignets, en bijna ieder zonder uitzondering is daarop verzot. Tom Tom wordt bereid door de bananen niet geheel gaar te koken en tot een stijf deeg te stampen. Dit deeg wordt in de soep gebruikt. In de lengte gesneden bananen worden ook in de zon gedroogd, gestampt en gezeefd. Dit meel heet gongotee, en wordt als hoofdvoedsel aan kinderen verstrekt.

.Het woord banana wordt bij de oudste schrijvers teruggevonden, zooals bij De Marees Beschrijvinge ende historische verhael vant Gout Koninckryck van Gunea, 1602, blz. 83 en in Begin ende Voortgangk,1646,behelzende de journalen dereerste Nederlandsche scheepvaarders op de Indiën, verzameld door I. Commelin, waar bij de eerste schipvaerdt op blz. 34 gesproken wordt van „Bananas oft Indiaensche Vygheboom", en op blz. 2 bij de tweede schipvaerdt gezegd wordt ,de Bananas is een fruyt van fatsoen als een beulingh ende van smaeck als Bargamotten oft mantjens peeren in ons landt". Ook Dapper maakt in zijn Gedenkwaardig bedryf der Ned. Oost-Indische Maetschappye, op de kuste en in het Keizerryk van Taising of Sina, 1670 op blz. 221, en Herlein in zijn Beschryving van de volk- plantinge Zuriname, 1718, op blz. 224 melding van de ,,bananas- boom".

In de tweede plaats noemen we de bacove, in het Engelsch genoemd banana, in het Negerengelsch bakoeba, in het Papiementsch bacoba, in het Maleisch pisang. Deze in Nederland bekende tafelvrucht, welke in ons land, evenals elders, groote populariteit heeft verworven, wordt rauw gebruikt, in tegenstelling met de banana.

Men onderscheidt in Suriname vijf voorname soorten van de bacove: de dwergbacove, waarschijnlijk in de 2de helft der 19de eeuw ingevoerd (Musa Cavendishii), de Indiaansche bacove met wijnroode vruchten, de banana-bacove, veel gelijkende op de 
„Gros Michel” of Jamaica bacoven, waarmede de aanplant voor uitvoer uit Suriname was begonnen, welke toen de Panamaziekte deze soort had verwoest, door de Congo bacove werd vervangen, de appelbacove, die iets frisscher van smaak en zuurder is, en de ,ladies finger (Pikien Misi vinga).

Van bacoven werden ook bacovenvijgen gemaakt. De vrucht werd gedroogd en had groote voedingswaarde door de suiker en bevatte niet de pitten van de vijgen. Van bacoven werd in ons land bacovenmeel vervaardigd. Voor de bereiding van alcohol kunnen zoowel rijpe als de onrijpe vruchten worden gebruikt. Het sap van de vrucht en het blad kan als kleurstof dienen, en de stam, zoowel van bananen als van bacoven, voor de bereiding van garen en papier uit de vezelstoffen. De waarde van de vezel wordt op $1 / 3$ der manillahennip geschat. Een stam van $37 \mathrm{~kg}$. (zonder bladeren) kan 0,44 kg. vezel opleveren. Tot nu toe is met een dergelijke nijverheid geen aanvang gemaakt en duizenden stammen worden jaarlijks als waardeloos weggeworpen.

De Nederlandsche Maatschappij ter bevordering van Nijverheid loofde in 1853 haar gouden medaille uit voor de best geslaagde proeven om wit- en pakpapier uit deze stof te vervaardigen en bovendien gedurende drie jaren een belooning van honderd gulden voor wie bewijzen kon leveren van voortdurend debiet dezer nieuwe tak van nijverheid. Na het verstrijken van dezen termijn herhaalde zij haar prijsvraag. Hierop vestigde jhr. C. A. van Sypesteyn, de latere gouverneur van Suriname, in 1855 in deel I van het niet meer bestaande tijdschrift West-Indië nog de aandacht. Een ondernemend Surinamer, Jacques Nassy, heeft meer dan een kwart eeuw geleden plannen voor deze nijverheid gemaakt, maar hij moest uit gebrek aan middelen zijn pogingen staken.

Wat de naam bacove aangaat, kan het volgende worden medegedeeld. Het woord bacove wordt thans alleen in Suriname gebruikt. In verschillende woordenboeken, welke over de Nederlandsche taal der 16de en 17de eeuw handelen, zal men tevergeefs naar dit woord bacove zoeken ofschoon toch verschillende schrijvers er melding van hebben gemaakt. Zoo treffen wij het woord bacove aan in het reeds genoemde werk van $\mathrm{P}$. D(e) $\mathrm{M}$ (arees), waarin deze op blz 94 schrijft ,Deze Bachovens (onder ons Nederlanders alsoo genaemt) is bij naer het fatsoen als de Banana". In de Itinerario van Jan Huygen van Linschoten, 1595, teekent Paludanus op blz. 78 aan: „Indiaensche Vyghen [waarmede bananen worden bedoeld] worden van de Brasilianen 
Pacona ende den boom Paquover gheheeten". Piso noemt in De Indiae utriusque re naturali et medica Libri quatuordecim, 1658, op blz. 154 de namen pacobete en pacobuco. De laatstgenoemde is de naam van de soort, die de botanici Musa sapientum noemen, en pacobete de naam van de Musa paradisidiaca, die in Suriname baccove (elders baccovo, pacoba) wordt geheeten.

In het te voren genoemde werk van Herlein wordt op blz. 224 melding gemaakt van den „Bananas-boom”, maar in de Annotatie op dit werk, door gouverneur Nepveu geschreven in 1769, wordt op blz. 242 en 244 gewag gemaakt van de ,,bananasboom” en de ,,bakkove boom”, van welke laatste hij zegt: „Wordende by de Franschen Passie vygen genaamt omdat als men die over dwars snyd telkens zig een figuur in 't hart vertoont als een kruys met kleine swarte Nagels" enz.

Bellin zegt in zijn Description géographique de la Guyane, 1765 op blz. 139: „La Baccove, espèce de Banane”. Fermin schrijft op blz. 151 in Histoire naturelle de Hollande équinoxiale, 1765: „Bacove, Bacoba, est une sorte de Bananas".

In de Beschrijving van Guiana, van Hartsinck, 1770, komt op blz. 55 het volgende voor: „De Bakovens of Vygeboom is een zeer aangename en gezonde Vrucht, groeiende aan een Heester gelyk de Bananes". Vervolgens lezen wij in Blom: Verhandeling over den landbouw in de colonie Suriname, 1786, blz. 408 „Bacove is de kleine Pisang, Banannen is de groote Pisang.

Ten slotte moge hier gewezen worden naar de notulen van den Raad van Politie van 6 Maart 1694, waarin te lezen staat: „,Tot verval van de nodige lasten van predikanten, schoolmeesters etc. zullen de coloniers 25 stuivers van 't duysent over de consumptie van Cassave, patates, jammen, tayers, pees, coren, bannanes en backovens moeten betalen".

Ofschoon eenigszins verbasterd is het woord bacove, dat alleen in Suriname burgerrecht heeft verkregen, via de Portugeezen uit Brazilië tot ons gekomen, zooals blijkt uit het in 1912 verschenen werk der Linschoten Vereeniging: Beschryvinge ende historisch verhael, hiervoren genoemd, gelijk de heeren S. P. l'Honoré Naber en G. P. Rouffaer in een tweetal noten op blz. 169 en 171 aantoonen. In het Spaansch is de benaming bacova (voor de vrucht) en bacovo (voor de plant). De Encyclopaedie van Ned. West-Indië meent, dat zulks waarschijnlijk heeft plaats gehad door de groote Indiaansche volkstam, oorspronkelijk in Braziliaansch en Fransch Guyana tehuis, welke zich vóór 1500 sterk naar het zuiden had uitgebreid. 
In Nederland is het woord niet doorgedrongen, zelfs niet toen het Surinaamsche gouvernement op 21 Mei 1906 met de Amerikaansch „United Fruit Company” een overeenkomst gesloten had om deze vruchten op groote schaal uit te voeren en de eerste bacovenverscheping op 12 Juli 1906 naar Nederland plaats had met bacovenbooten. Deze bacoventragedie, waarin eenige millioenen verdwenen zijn, eindigde met de likwidatie in 1912.

Litteratuur, voorzoover niet genoemd in het artikel zelf: Overzicht van de Cultuurgewassen en Boschproducten van Suriname, door C. J. Hering, 1903; Kol. Weekblad 1912, nos 8 en 1913 No. 10; Geschiedkundige aanteekeningen van Suriname en Paramaribo, door Fred. Oudschans Dentz, 1912. 